\title{
Leksell Gamma Knife treatment for pilocytic astrocytomas: long-term results
}

\author{
Gabriela Simonova, MD, ${ }^{1}$ Petra Kozubikova, MSc, ${ }^{1-3}$ Roman Liscak, MD, ${ }^{1}$ and \\ Josef Novotny Jr., PhD ${ }^{1-3}$ \\ Departments of ${ }^{1}$ Stereotactic and Radiation Neurosurgery and ${ }^{2}$ Medical Physics, Na Homolce Hospital, Prague; and \\ ${ }^{3}$ Department of Dosimetry and Application of lonizing Radiation, Faculty of Nuclear Science and Physical Engineering, \\ Czech Technical University in Prague, Czech Republic
}

OBJECTIVE The purpose of this study was to evaluate long-term treatment results, radiation-related toxicity, and prognostic factors for the progression-free survival (PFS) of patients with pilocytic astrocytomas treated by means of stereotactic radiosurgery with a Leksell Gamma Knife.

METHODS A total of 25 patients with pilocytic astrocytomas underwent Gamma Knife surgery during the period 1992-2002. The median target volume was $2700 \mathrm{~mm}^{3}$ (range 205-25,000 mm 3 ). The 18 patients treated with 5 daily fractions received a median minimum target dose of $25 \mathrm{~Gy}$. Doses for the 2 patients treated with 10 fractions over 5 days ( 2 fractions delivered on the same day at least 6 hours apart) were 23 and $28 \mathrm{~Gy}$. For the 5 patients treated with a single fraction, the minimum target dose ranged from 13 to $20 \mathrm{~Gy}$ (median $16 \mathrm{~Gy}$ ).

RESULTS Complete regression occurred in 10 patients (40\%) and partial regression in 10 patients (40\%). The 10-year overall survival rate was $96 \%$ and the 10 -year PFS rate was $80 \%$. Target volume appeared to be a significant prognostic factor for PFS ( $p=0.037)$. Temporary Grade 3 toxicity appeared in 2 patients $(8 \%)$, and these patients were treated with corticosteroids for 2 months. Permanent Grade 4 toxicity appeared in 2 patients (8\%) and was associated with neurocognitive dysfunction. In these 2 individuals, the neurocognitive dysfunction was also felt to be in part the result of the additional therapeutic interventions ( 4 in one case and 6 in the other) required to achieve durable control of their tumors. CONCLUSIONS Radiosurgery represents an alternative treatment modality for small residual or recurrent volumes of pilocytic astrocytomas and provides long-term local control. Target volume appears to be the most important factor affecting PFS.

http://thejns.org/doi/abs/10.3171/2015.10.PEDS14443

KEY WORDS pilocytic astrocytoma; neurosurgical resection; stereotactic radiosurgery; radiotherapy; Gamma Knife

$\mathrm{P}$ ILOCYTIC astrocytomas are brain tumors of children and adolescents; $75 \%$ are diagnosed in the first 2 decades of life, most frequently during the first decade. Although they represent between $1 \%$ and $5 \%$ of all intracranial tumors and $1.7 \%-7 \%$ of glial tumors, pilocytic astrocytomas are common brain tumors in children (representing 70\%-80\% of cerebellar astrocytomas). ${ }^{3,8,27}$ Most are located in the cerebellar hemispheres, in the vermis, in the third and fourth ventricles, in the hypothalamus, and in the parasellar region. Radical neurosurgical resection provides the best therapeutic results and remains the main therapy option for low-grade gliomas. . $^{3,8,10,13,18,25,29}$ Howev- er, the optimal treatment strategy for pilocytic astrocytomas following subtotal neurosurgical resection or for unresectable tumors has not been strictly defined and remains controversial. The consensus seems to favor observation and delaying radiotherapy until recurrence or progression is detected clinically or by imaging. Other treatment modalities include fractionated external beam radiation therapy (EBRT), chemotherapy, stereotactic radiotherapy (using an optimal fractionation scheme), and radiosurgery (a single radiation fraction). 5, $, 6,9,11,12,14,16,17,19,20,23,27$ Radiation therapy is not recommended for very young children (under the age of 3 years) because it is associated with a high

ABBREVIATIONS BED = biologically effective dose; EBRT = external beam radiation therapy; EORTC = European Organization for Research and Treatment of Cancer; FLT PET = 18F-fluorothymidine positron emission tomography; GKS = Gamma Knife surgery; KPS = Karnofsky Performance Status; PFS = progression-free survival; PLT = planning target volume; RTOG = Radiation Therapy Oncology Group.

SUBMITTED May 27, 2014. ACCEPTED October 29, 2015.

INCLUDE WHEN CITING Published online March 18, 2016; DOI: 10.3171/2015.10.PEDS14443. 
risk of serious postradiation damage. ${ }^{25,29}$ Depending on the patients' age and future prospects and treatment methods, 3 groups of patients could be defined: 1) patients with completely resected tumors, 2) patients with subtotally resected tumors, and 3) patients who have undergone biopsy but not resection (i.e., those with unresectable tumors).

Patients with completely resected tumors do not require further treatment, and long-term observation is an adequate approach in these cases. Subtotal neurosurgical resections are often combined with postoperative fractionated radiotherapy, and over the past 3 decades stereotactic radiation methods have become increasingly used for the treatment of residual tumors. ${ }^{9-17,28}$ Pilocytic astrocytomas tend to proliferate very slowly, and the evaluation of treatment results requires prolonged follow-up (at least 10 years) after total resection. ${ }^{3,8,13,18,25,29}$ Malignant transformation of pilocytic astrocytomas and meningeal infiltration has only rarely been described. ${ }^{1,2,7,24}$

\section{Methods}

During a 10-year period from 1992 to 2002,25 patients (19 boys and 6 girls) with histologically verified pilocytic astrocytomas underwent stereotactic irradiation with a Leksell Gamma Knife (Elekta AB; Gamma Knife surgery [GKS]). The patients' median age was 13 years (range 3-17 years), and the age distribution is presented in Table 1. Clinical manifestations were dependent on the location of the tumor. Table 1 shows the patients' neurological symptoms and the location of their tumors.

Microsurgical removal of pilocytic astrocytoma was considered as a first choice of treatment in all patients. If open surgery was not indicated (e.g., because of risky anatomical location or complicated course of previous surgery) or was declined by the informed patient or his/ her parents, then radiosurgery was considered as a second choice treatment. In 6 cases (24\%), GKS was used as a primary definitive treatment after a stereotactic biopsy. In 13 cases (52\%), the patients underwent tumor resection followed by GKS. In another 6 cases (24\%), the patients underwent EBRT prior to GKS; in 4 of these 6 cases, the patients underwent neurosurgical resection before EBRT and in the other 2 cases, they underwent stereotactic biopsy without resection.

Single-session radiosurgery was considered for the patients with small tumors and no critical anatomical structures in the close vicinity of the tumor. Otherwise a fractionated scheme of radiosurgery was selected. Our first experience with a fractionation scheme was reported in Radiotherapy and Oncology. ${ }^{26}$ Using the Gamma Knife, it is possible to guarantee consistency in dose delivery from fraction to fraction, by leaving the stereotactic frame attached to the patient's head during the entire course of treatment, which was 5 days in our group of patients. The position of the frame on our patients was verified over the whole treatment course using 2 independent control methods.

The distances between the center of the Leksell stereotactic space and certain points on the outer boundary of the patient's skull were measured using a skull scaling instrument that is attached to the stereotactic frame fixed
TABLE 1. Patient demographics and clinical characteristics

\begin{tabular}{|c|c|}
\hline Characteristic & Value \\
\hline \multicolumn{2}{|l|}{ Age in years } \\
\hline $3-5$ & $4(16 \%)$ \\
\hline $6-10$ & $3(12 \%)$ \\
\hline $11-15$ & $11(44 \%)$ \\
\hline $16-17$ & $7(28 \%)$ \\
\hline \multicolumn{2}{|l|}{ Sex } \\
\hline Male & $19(76 \%)$ \\
\hline Female & $6(24 \%)$ \\
\hline \multicolumn{2}{|l|}{ 1st neurological symptom } \\
\hline Headache & $12(48 \%)$ \\
\hline Nausea, vomiting & $4(16 \%)$ \\
\hline Vertigo & $3(12 \%)$ \\
\hline Imbalance & $2(8 \%)$ \\
\hline Visual symptoms & $2(8 \%)$ \\
\hline Hemiparesis & $1(4 \%)$ \\
\hline Psychosyndroma & $1(4 \%)$ \\
\hline \multicolumn{2}{|l|}{ Location of tumor } \\
\hline 3rd \&/or 4th ventricle & $9(36 \%)$ \\
\hline Cerebellar region & $5(20 \%)$ \\
\hline Pons, midbrain & $4(16 \%)$ \\
\hline Basal ganglia & $3(12 \%)$ \\
\hline Parasellar & $2(8 \%)$ \\
\hline \multicolumn{2}{|l|}{ Fractionation scheme } \\
\hline Single fraction & $5(20 \%)$ \\
\hline 5 fractions in 5 days & $18(72 \%)$ \\
\hline 10 fractions in 5 days & $2(8 \%)$ \\
\hline \multicolumn{2}{|l|}{ Surgical \& RT management } \\
\hline GKS as primary Tx & $6(24 \%)$ \\
\hline Neurosurgical procedure prior to GKS & $13(52 \%)$ \\
\hline EBRT prior to GKS & $2(8 \%)$ \\
\hline Neurosurgical procedure \& EBRT prior to GKS & $4(16 \%)$ \\
\hline \multicolumn{2}{|l|}{ Target volume in $\mathrm{mm}^{3}$} \\
\hline Median & 2700 \\
\hline Range & $205-25,000$ \\
\hline \multicolumn{2}{|l|}{ BED in Gy } \\
\hline Median & 87.5 \\
\hline Range & $60-220$ \\
\hline
\end{tabular}

$\mathrm{BED}=$ biologically effective dose; $\mathrm{RT}$ = radiotherapeutic; $\mathrm{Tx}=$ treatment.

to the patient's head. These measurements were carried out before every daily fraction. If the measured distances for all chosen points were identical (with a tolerance of $0.5 \mathrm{~mm}$ ) over the whole fractionated regimen (before each fraction) it was assumed that the position of the stereotactic frame was identical to that used for the first fraction.

A new stereotactic MRI investigation was performed, subsequent to the original one used for target localization (usually before the third fraction). The original treatment plan was superimposed on the MR images from this new study, and the target volume coverage and doses to critical structures were compared with the original plan. The tests 


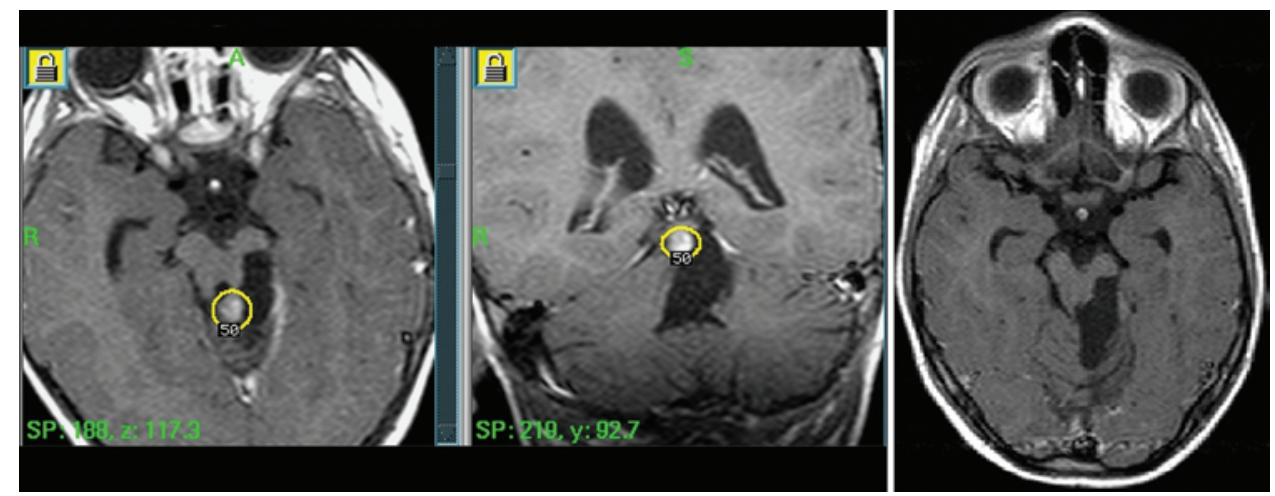

FIG. 1. Representative images obtained in a 16 -year-old patient with pilocytic astrocytoma in the vermis cerebelli (tumor dimensions $4 \times 7 \times 6 \mathrm{~mm}$, gross tumor volume $500 \mathrm{~mm}^{3}$, minimum dose of 19 Gy prescribed to the $50 \%$ isodose line, 1 fraction, no late toxicity). Left: Treatment planning MR images. Right: Follow-up axial postcontrast T1-weighted MR image obtained 82 months after GKS. Figure is available in color online only.

performed in our study showed a very stable frame position and support the feasibility of using fractionation with a fixed stereotactic frame. Moreover, the regimen was tolerated by all patients.

The fractionation scheme was selected according to 1) the previous treatment modality (fractionated scheme for all patients pretreated by EBRT); 2) the location of the lesion (a fractionated scheme was used in tumors located in an eloquent region or in those which were in contact with the brainstem; in cases involving contact with the optic pathway 10 fractions were used over a period of 5 days, with the time interval between fractions being longer than 6 hours); and 3) larger volumes. Patients irradiated with a single fraction had the following characteristics: no previous EBRT, cerebellar location without contact with the brainstem or optic nerve, tumor volume not larger than $4800 \mathrm{~mm}^{3}$, and repeat resection not recommended by neurosurgeons (Fig. 1).

\section{Treatment Parameters}

We used the following fractionation scheme: 5 patients were irradiated with a single fraction (cerebellar location, no previous EBRT, and smaller volumes of 205-4800 $\left.\mathrm{mm}^{3}\right), 18$ patients were treated in 5 daily fractions, and 2 patients were treated with 10 fractions over 5 days (lesions in contact with optic pathway) - with an interval of at least 6 hours between consecutive fractions. Eighteen patients treated with 5 daily fractions received a total minimum target dose of 20-30 Gy (median 25 Gy). Doses for 2 patients treated with 10 fractions over 5 days were 23 and $28 \mathrm{~Gy}$. For 5 patients treated with a single fraction the minimum target dose ranged from 13 to 20 Gy (median 16 Gy). The radiation dose was prescribed with respect to the following conditions: the number of fractions $(\alpha / \beta$ considered as $2 \mathrm{~Gy}$ ), previous irradiation (5 patients received radiotherapy), planning target volume (PTV), and age. PTV was defined according to postcontrast T1-weighted MR images as enhancing tissue alone. The median of PTV was 2700 $\mathrm{mm}^{3}$ (range 205-25,000 $\mathrm{mm}^{3}$ ). The biologically effective dose (BED) was calculated applying the formula: $\mathrm{BED}=\mathrm{n}$ $\times \mathrm{d} \times(1+[\mathrm{d} /(\alpha / \beta)])$, where $\mathrm{n}$ stands for the number of fractions, $\mathrm{d}$ for the applied dose per fraction, and the ratio $\alpha / \beta$ characterizes tissue and its response to radiation. In our case we used $\alpha / \beta=2 \mathrm{~Gy}$. BED was calculated only for the GK fractionation regimen (e.g., EBRT was not included). The median BED was 87.5 Gy (range 60-220 Gy).

Follow-up consisted of regular clinical neurological examinations and neuroradiological studies. MRI studies were performed in all cases (native T1-weighted, protondensity, T2-weighted, and postcontrast T1-weighted images obtained in the axial and coronal projections), and in selected cases 18 F-fluorothymidine positron emission tomography (FLT PET) was also performed. The minimum duration of follow-up for survivors was 10 years, and the median duration of follow-up was 181 months (15 years). MRI was performed 6 months after GKS, 1 year after GKS, and then annually thereafter for the first 10 years. From 10 years after GKS on, MRI was performed every 2 years. The solid part of pilocytic astrocytomas is well defined on postcontrast T1-weighted MR images, the cystic part on T2-weighted and proton-density images. Pilocytic astrocytomas are well demarcated from the surrounding healthy tissue and have no evident infiltrative growth. The tumor response was classified in 4 categories and evaluated at the time of the clinical and neuroradiological follow-up: complete regression, no evidence of a lesion on MRI; partial regression, more than a $50 \%$ reduction in initial tumor volume; stabilization, no tumor volume change; progression, tumor volume growth of at least $25 \%$ or more after GK irradiation. The assessment of acute and late toxicity followed the established and generally accepted RTOG/ EORTC (Radiation Therapy Oncology Group/European Organization for Research and Treatment of Cancer) scoring system. The quality of the patient's life was evaluated by the improvement in the Karnofsky Performance Status (KPS) score calculated at the last follow-up and the possibility of their further education and employment. In our series the pretreatment KPS score was $100 \%$ in 4 patients, $80 \%-90 \%$ in 17 patients, $70 \%$ in 2 patients, and $40 \%$ in 1 patient.

\section{Statistical Analysis}

The radiation-related toxicity was evaluated using the RTOG/EORTC criteria. We analyzed variables affecting 
progression-free survival (PFS) after GKS (age, volume, sex, BED, previous radiotherapy) in the entire group of patients. The patient group was categorized for individual parameters as follows: age (13 years as a median value), PTV (2700 $\mathrm{mm}^{3}$ as a median value), sex (female, male), and BED (87.5 Gy as a median value). Univariate survival analyses were performed using the Kaplan-Meier method, and treatment comparisons were made with the log-rank test. Statistical analysis was performed using the SPSS Statistical Software Package (IBM SPSS Statistics 20). Differences were considered statistically significant if the $\mathrm{p}$ value was $<0.05$.

\section{Results}

For the entire group of 25 patients, actual overall survival was $96 \%$ at 10 years; 1 patient died from malignant transformation and tumor progression 53 months after GKS (Fig. 2). Complete regression was found in 10 patients (40\%), with a median time to response of 43 months (range 22-62 months); partial regression was seen in 10 patients $(40 \%)$, with a median time to response of 21 months (range 12-78 months). An example of tumor regression after GKS is documented in Fig. 3. In 4 patients, progression of the cystic component occurred during the follow-up period (in 3 patients after previous partial regression); 1 of these 4 patients underwent neurosurgical resection, and the other 3 patients underwent stereotactic aspiration of the cyst. During further follow-up these 4 patients had no other progression, and 3 of them are surviving with no evidence of neurological symptoms. The overall PFS, broken down by size of the target volume, is documented in Fig. 4. The PFS was significantly better in patients with a planning target volume (PTV) of 2700 $\mathrm{mm}^{3}$ or less $(\mathrm{p}=0.037)$. Univariate statistical analysis did not show any difference in PFS resulting from: age, sex, location of the tumor or BED. Temporary Grade 3 toxicity appeared in 2 patients (8\%), who received corticosteroids for 2 months. Permanent Grade 4 toxicity appeared in 2 patients (8\%) and was associated with neurocognitive dysfunction cumulative with previous procedures including 4 and 6 therapeutic interventions (repeat resection and EBRT). Because these patients underwent several therapeutic interventions, including ventriculoperitoneal shunt placement and EBRT, it was difficult to identify the main cause of the toxicity.

\section{Quality of Life}

Four patients had had a KPS score of $100 \%$ before radiosurgery, and their scores did not change after GKS. In 17 patients the KPS score improved approximately 10 percentage points after GKS (from 70\%-90\% to $80 \%-100 \%$ ). One patient whose KPS score was $40 \%$ before GKS died of malignant transformation. Two patients with pretreatment KPS scores of $90 \%$ experienced worsening of approximately 10 percentage points, and 1 patient who had a pretreatment KPS score of $80 \%$ showed no change in KPS score during follow-up.

Since the patients are children and adolescents, good therapeutic results can also be documented by psychosocial inclusion, completion of education, employment in

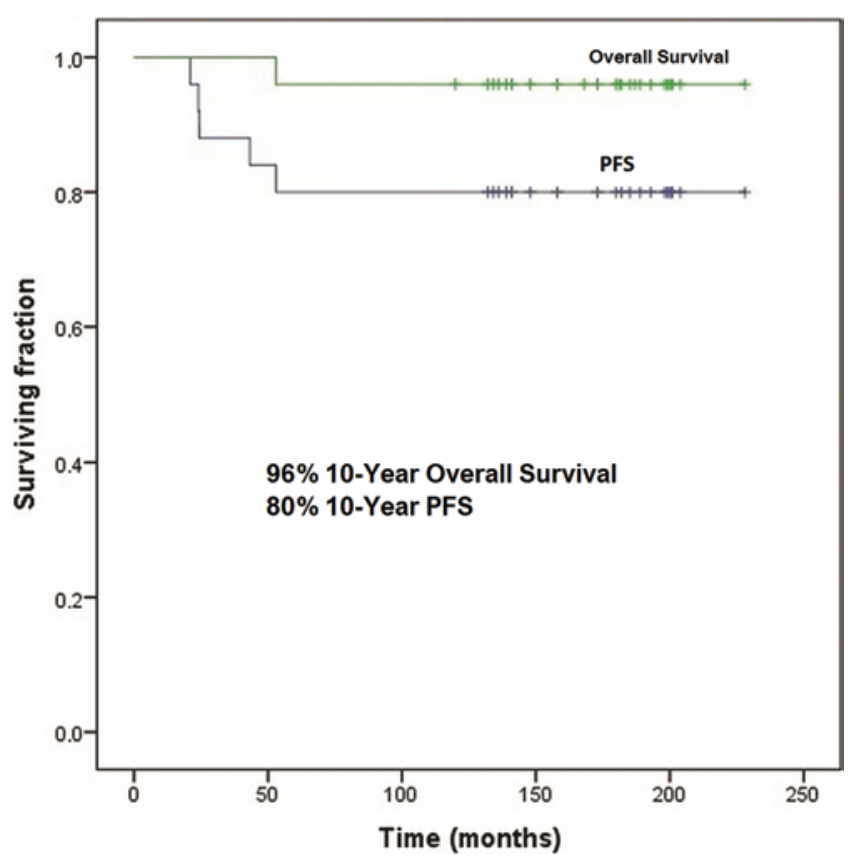

FIG. 2. Overall and progression-free survival for the entire group of 25 patients. Figure is available in color online only.

adulthood, and the possibility of starting a family. Of the 25 patients in this case series, 9 are currently (as of this writing) over 25 years old: 2 patients are fully disabled (one underwent repeat surgical resection and EBRT and the other underwent repeat neurosurgery, EBRT, stereoevacuation, and ventriculoperitoneal shunt placement), 2 patients are reliant on a partial disability pension (after graduating from high school), 1 patient is a full-time working chef, 2 patients are working in administration full-time (after graduating from high school), and 2 of the treated female patients have had healthy babies and are currently on maternity leave (both graduated from high school and one is continuing her education at university).

\section{Discussion}

Pilocytic astrocytomas typically have a relatively small portion of cells in the proliferative phase of the cell cycle, and the radiation response (tumor regression) and radiation-related toxicity can be expected years later., 3,810,13,29 Recurrence can be observed several years after treatment. The minimum duration of follow-up is considered to be 10 years. The most beneficial therapeutic method with the best results is complete neurosurgical resection (associated with a 10-year PFS rate of 95\%).,3,10,13,28 Treatment of the postoperative residual tumor or a tumor for which surgery cannot be undertaken as the primary treatment (due to its location in the brain) is still controversial and should also take into account the patient's age. For small children it is better to consider repeat neurosurgical resection before radiotherapy and, if the residual lesion does not progress, to delay radiation therapy until the patient is older. Radiotherapy is not indicated for very small children under the age of 3 years due to the high risk of severe radiation damage. In the case of tumor progression in these young 


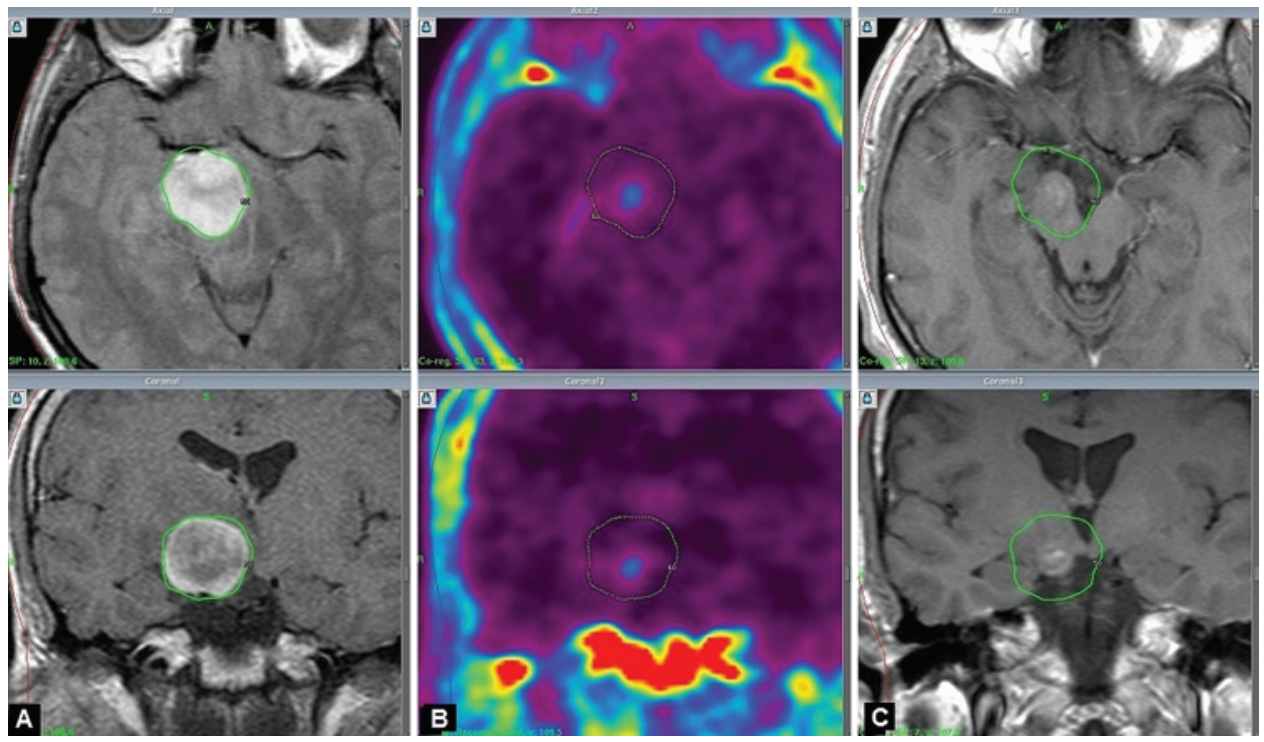

FIG. 3. Representative images obtained in a 14-year-old patient with pilocytic astrocytoma in the right mesencephalon (tumor dimensions $31 \times 30 \times 28 \mathrm{~mm}$, gross tumor volume $15,000 \mathrm{~mm}^{3}$, minimum dose 21.25 Gy prescribed to the $50 \%$ isodose line, administered in 5 daily fractions, no late toxicity). The upper row shows axial images and the lower row shows corresponding coronal images. A: Treatment-planning MR images (postcontrast, T1-weighted). B: PET follow-up after 112 months. C: Postcontrast T1-weighted follow-up MR images obtained after 145 months. Figure is available in color online only.

patients, chemotherapy can be considered as another therapeutic alternative to neurosurgical resection. ${ }^{19,20}$

Treatment options remain controversial in patients who show progression of a cystic component of the tumor progression on follow-up MRI. In cases of symptomatic cysts, therapy is primarily stereotactic aspiration or reoperation..$^{3,8,17}$ Some authors have carried out stereotactic aspiration of cystic components prior to irradiation and have combined this with intracavitary brachytherapy using phosphorus. ${ }^{12,17}$ Development of conformal stereotactic techniques (radiosurgery and radiotherapy with photonsusing a Gamma Knife, linear accelerator, or CyberKnifeor proton therapy) enables a highly conformal plan to be achieved with a sharp dose fall-off outside the target volume. For this reason the risk of post-radiation damage to the brain tissue should be significantly lower than with standard fractionated EBRT..$^{10-12,14,16,23,27}$ The recommended radiation dose for fractionated EBRT is in the range of 40-54 Gy (depending on the age of the patient). Clinical trials have not confirmed the benefit of radiation dose escalation above this range. In one case series involving 37 patients undergoing multimodal treatment for pilocytic astrocytoma, the radiosurgical dose to the tumor margin ranged from 9.6 to $22.5 \mathrm{~Gy}$ (median $15 \mathrm{~Gy}$ ). ${ }^{11}$

One of the possibilities of comparing radiation applied doses from EBRT or stereotactic hypo-fractionation radiotherapy seems to be the calculation of biologically effective doses (BEDs). A linear quadratic model can be used to determine the dose per fraction for hypo-fractionated stereotactic radiotherapy on the basis of an equivalent biological dose for tumors or brain tissues but should only be used as a guide and needs to be confirmed by clinical trials. Other factors, such as tumor volume size, the possibility of tumor growth during fractionation, and the implication of vascular damage, are important considerations that have not been incorporated in this model..$^{15}$ Some authors do not recommend the linear quadratic model for doses over 8-10 Gy. ${ }^{3,22}$

There is a still relatively small amount of data on the results of these treatment methods, due to the fact that the patients have to be followed and monitored for many years after treatment (a minimum of 10 years), with the preferred follow-up period even longer than 10 years.

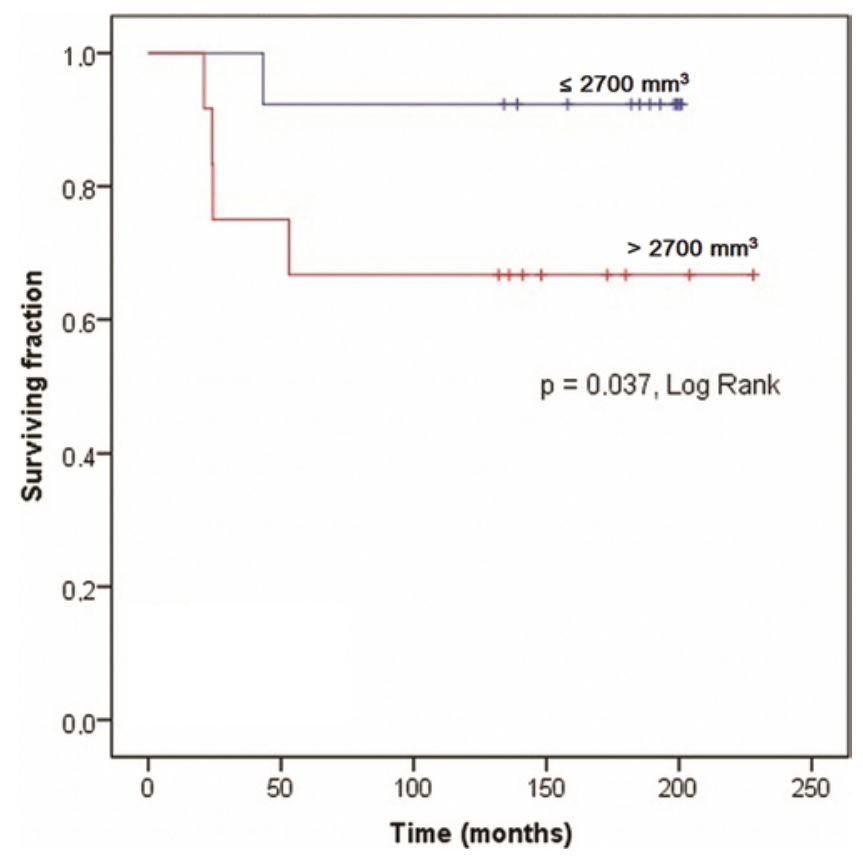

FIG. 4. Progression-free survival as a function of the size of the target volume (median $2700 \mathrm{~mm}^{3}$ ). Figure is available in color online only. 
The evaluation includes not only the local therapeutic effect and side effects but also the quality of life of treated patients. Long-term survivors, especially children who have had a brain tumor or who have had intensive nervous system therapy, appear to be most at risk for cognitive, social, and adjustment difficulties. ${ }^{4,12,21}$ Psychological examination, evaluation of neurocognitive functions, and IQ tests are recommended for these long-surviving patients. Some authors have reported neurocognitive dysfunction and reduced IQ in some patients at the time of diagnosis. Hydrocephalus and multiple therapeutic interventions seem to be risk factors for these parameters. In the absence of initial tests, it is difficult to assess whether changes were already present before treatment or whether they were caused by the treatment procedures. An important element of the evaluation of the therapeutic results also involves psychosocial aspects: the realistic chance of a full and satisfying life in the future, the possibility of education, employment, starting a family, and the opportunity to realize personal interests and activities.

The main limitation of this retrospective study is the inhomogeneous patient population, including different fractionation schemes for GKS, and different prior therapeutic interventions, involving EBRT and neurosurgical procedures.

The definitive appreciation of conformal radiation treatment methods (including GKS) still has a common methodological problem: a sample limitation owing to the relatively small number of long-term surviving pediatric patients with pilocytic astrocytomas in the reported series.

\section{Conclusions}

Each therapeutic intervention for these usually benign tumors increases the risk of late complications and impairment of the patients' quality of life. The careful management of the treatment procedure for patients with pilocytic astrocytomas is important in relation to generally long life perspectives.

Radiosurgery and stereotactic radiotherapy have significantly expanded treatment possibilities for brain tumors with a sparing effect on critical brain structures, although the volume of the tumor is a limiting factor. Radiosurgery, with its low rate of radiation-related late toxicity and effective long-term local tumor control, provides a treatment option for patients with residual, recurrent, or unresectable pilocytic astrocytomas in whom neurosurgery and fractionated EBRT have failed.

\section{Acknowledgments}

The paper was supported by the Ministry of Health, Czech Republic-conceptual development of research organization (Nemocnice Na Homolce [NNH] 00023884).

\section{References}

1. Broniscer A, Baker SJ, West AN, Fraser MM, Proko E, Kocak M, et al: Clinical and molecular characteristics of malignant transformation of low-grade glioma in children. J Clin Oncol 25:682-689, 2007

2. Bernell WR, Kepes JJ, Seitz EP: Late malignant recurrence of childhood cerebellar astrocytoma. Report of two cases. $\mathbf{J}$ Neurosurg 37:470-474, 1972
3. Cohen KJ, Broniscer A, Glod J: Pediatric glial tumors. Curr Treat Options Oncol 2:529-536, 2001

4. Constine LS, Woolf PD, Cann D, Mick G, McCormick K, Raubertas RF, et al: Hypothalamic-pituitary dysfunction after radiation for brain tumors. N Engl J Med 328:87-94, 1993

5. Conway PD, Oechler HW, Kun LE, Murray KJ: Importance of histologic condition and treatment of pediatric cerebellar astrocytoma. Cancer 67:2772-2775, 1991

6. Dirks PB, Jay V, Becker LE, Drake JM, Humphreys RP, Hoffman HJ, et al: Development of anaplastic changes in low-grade astrocytomas of childhood. Neurosurgery 34:6878,1994

7. Due-Tønnessen BJ, Lundar T, Egge A, Scheie D: Neurosurgical treatment of low-grade cerebellar astrocytoma in children and adolescents: a single consecutive institutional series of 100 patients. J Neurosurg Pediatr 11:245-249, 2013

8. Fisher PG, Tihan T, Goldthwaite PT, Wharam MD, Carson BS, Weingart JD, et al: Outcome analysis of childhood lowgrade astrocytomas. Pediatr Blood Cancer 51:245-250, 2008

9. Garcia DM, Marks JE, Latifi HR, Kliefoth AB: Childhood cerebellar astrocytomas: is there a role for postoperative irradiation? Int J Radiat Oncol Biol Phys 18:815-818, 1990

10. Grabenbauer GG, Schuchardt U, Buchfelder M, Rödel CM, Gusek G, Marx M, et al: Radiation therapy of optico-hypothalamic gliomas $(\mathrm{OHG}$-radiographic response, vision and late toxicity. Radiother Oncol 54:239-245, 2000

11. Hadjipanayis CG, Kondziolka D, Gardner P, Niranjan A, Dagam S, Flickinger JC, et al: Stereotactic radiosurgery for pilocytic astrocytomas when multimodal therapy is necessary. J Neurosurg 97:56-64, 2002

12. Kazak AE: Evidence-based interventions for survivors of childhood cancer and their families. J Pediatr Psychol 30:29-39, 2005

13. Kehler U, Arnold H, Müller H: Long-term follow-up of infratentorial pilocytic astrocytomas. Neurosurg Rev 13:315320, 1990

14. Kortmann RD, Timmermann B, Taylor RE, Scarzello G, Plasswilm L, Paulsen F, et al: Current and future strategies in radiotherapy of childhood low-grade glioma of the brain. Part I: Treatment modalities of radiation therapy. Strahlenther Onkol 179:509-520, 2003

15. Liu L, Bassano DA, Prasad SC, Hahn SS, Chung CT: The linear-quadratic model and fractionated stereotactic radiotherapy. Int J Radiat Oncol Biol Phys 57:827-832, 2003

16. Mansur DB, Rubin JB, Kidd EA, King AA, Hollander AS, Smyth MD, et al: Radiation therapy for pilocytic astrocytomas of childhood. Int J Radiat Oncol Biol Phys 79:829834, 2011

17. Niranjan A, Witham T, Kondziolka D, Lunsford LD: The role of stereotactic cyst aspiration for glial and metastatic brain tumors. Can J Neurol Sci 27:229-235, 2000

18. Ogiwara H, Bowman RM, Tomita T: Long-term follow-up of pediatric benign cerebellar astrocytomas. Neurosurgery 70:40-48, 2012

19. Packer RJ, Ater J, Allen J, Phillips P, Geyer R, Nicholson HS, et al: Carboplatin and vincristine chemotherapy for children with newly diagnosed progressive low-grade gliomas. J Neurosurg 86:747-754, 1997

20. Prados MD, Edwards MS, Rabbitt J, Lamborn K, Davis RL, Levin VA: Treatment of pediatric low-grade gliomas with a nitrosourea-based multiagent chemotherapy regimen. J Neurooncol 32:235-241, 1997

21. Packer RJ, Sutton LN, Atkins TE, Radcliffe J, Bunin GR, D'Angio G, et al: A prospective study of cognitive function in children receiving whole-brain radiotherapy and chemotherapy: 2-year results. J Neurosurg 70:707-713, 1989

22. Santacroce A, Kamp MA, Budach W, Hänggi D: Radiobiol- 
ogy of radiosurgery for the central nervous system. BioMed Res Int 2013:362761, 2013

23. Saunders DE, Phipps KP, Wade AM, Hayward RD: Surveillance imaging strategies following surgery and/or radiotherapy for childhood cerebellar low-grade astrocytoma. J Neurosurg 102 (2 Suppl):172-178, 2005

24. Scott RM, Ballantine HT Jr: Cerebellar astrocytoma: malignant recurrence after prolonged postoperative survival. Case report. J Neurosurg 39:777-779, 1973

25. Sievert AJ, Fisher MJ: Pediatric low-grade gliomas. J Child Neurol 24:1397-1408, 2009

26. Simonová G, Novotný J, Novotný J Jr, Vladyka V, Liscák R: Fractionated stereotactic radiotherapy with the Leksell Gamma Knife: feasibility study. Radiother Oncol 37:108-116, 1995

27. Somaza SC, Kondziolka D, Lunsford LD, Flickinger JC, Bissonette DJ, Albright AL: Early outcomes after stereotactic radiosurgery for growing pilocytic astrocytomas in children. Pediatr Neurosurg 25:109-115, 1996

28. Song CW, Park H, Griffin RJ, Levitt SH: Radiobiology of stereotactic radiosurgery and stereotactic body radiation therapy, in Levitt SH, Purdy JA, Perez CA, et al (eds): Technical Basis of Radiation Therapy. Berlin: Springer, 2012
29. Qaddoumi I, Sultan I, Broniscer A: Pediatric low-grade gliomas and the need for new options for therapy: Why and how? Cancer Biol Ther 8:4-10, 2009

\section{Disclosures}

Roman Liscak and Josef Novotny Jr. report being consultants with Elekta Instruments AB, Stockholm.

\section{Author Contributions}

Conception and design: Simonova. Acquisition of data: Simonova, Kozubikova. Analysis and interpretation of data: Simonova, Kozubikova. Critically revising the article: Liscak, Novotny. Reviewed submitted version of manuscript: Liscak. Statistical analysis: Kozubikova, Novotny. Study supervision: Simonova.

\section{Correspondence}

Gabriela Simonova, Na Homolce Hospital, Department of Stereotactic and Radiation Neurosurgery, Roentgenova 2, Prague 5, 150 30, Czech Republic. email: gabriela.simonova@homolka.cz. 